control. The indicators of prostaglandin metabolism are related to the $\mathrm{HbA}_{1}$ concentrations namely, to the different stages of diabetic control.

It is reasonable to suppose that the uncontrolled diabetic state and the shift in the balance of two antagonistic prostaglandins towards pathogenic direction might have a role in diabetic microangiopathy. Our observations support the authors' opinion.

L OROSZ M UDVARDY

Second Department of Medicine,

University Medical School

H-4012 Debrecen 12 ,

Hungary

A FEHER

$P$ VINCZE

L MADÁCSY

Second Department of Paediatrics,

Postgraduate Medical University,

Budapest,

Hungary

1 Brinchmann-Hansen O, Dahl-Jørgensen K, Sandvik L, Hanssen $\mathrm{KF}$. Blood glucose concentrations and progression of diabetic retionopathy: the seven year results of the Oslo study. $B M \mathcal{J}$ 1992;304:19-22. (4 January.)

2 Klein RK, Klein BEK, Moss SE, Davis MD, DeMets DL. Glycosylated haemoglobin predicts the incidence and progression of diabetic retinopathy. . $A M A$ 1988;260:2864-71.

\section{Treatment of hypertension in older adults}

SIR, - The recent report on the principal results of the Medical Research Council's trial of treatment of hypertension in older adults ${ }^{1}$ has led to a suggestion that hydrophilic and lipophilic $\beta$ blockers differ in terms of their cardioprotective effects. ${ }^{2}$ Such a suggestion deserves careful consideration in view of its widespread implications, if true.

Martin J Kendall invokes the literature on the long term use of $\beta$ blockers in secondary prevention as evidence for the hypothesis. ${ }^{2}$ This is indeed the most extensive and well documented source of controlled (and relevant) data. The original overview of the trials included over 20000 patients treated long term ${ }^{3}$; the updated analysis added two more trials, ${ }^{4}$ and to these should now be added the APSI trial,,$^{5}$ making a total of over 24000 patients.

The hydrophilicity of the $\beta$ blockers in these studies can be quantified by their distribution coefficients between octanol and aqueous buffer. ${ }^{67}$ Dividing the range of values of the distribution coefficients into equal and logical intervals on a logarithmic scale separated the $\beta$ blockers into four groups with similar degrees of hydrophilicity (see table) and had the added statistical advantage of dividing the clinical trials into four roughly equal sized groups in terms of total patient numbers. The apparent mortality benefit was calculated separately for each group of $\beta$ blockers over the relevant subset of trials using standard methodo-

No relation was immediately evident nor was it disclosed by more careful statistical testing either with a general test for heterogeneity ${ }^{3}\left(\chi_{3}^{2}=0.64\right.$, logy. ${ }^{3}$ The table shows the results.

$\mathrm{p}=0.89)$ or with a more specific test for trend in the odds ratio $\left(\chi^{2}=0.45, p=0.5\right)$. For each separate category of $\beta$ blockers there was a significant mortality benefit of a size consistent with the overall $22 \%$ reduction in mortality. More detailed analysis based on individual $\beta$ blockers led to the same conclusion.

Great care needs to be taken when assessing relations between the properties of individua $\beta$ blockers and their benefits. Even those thrown up by overviews themselves can be illusory. The original overview suggested that intrinsic sympathomimetic activity was an undesirable property based on mortality results ${ }^{3}$; subsequently analysis of non-fatal reinfarction and updating of the mortality data led one of the same authors to dismiss this finding. ${ }^{8}$

In terms of secondary prevention of mortality hydrophilic and lipophilic $\beta$ blockers seem to be equally cardioprotective.

Institute of Mathematics and Statistics,

J A LEWIS

University of Ken

Canterbury CT2 7N

1 Medical Research Council Working Party. MRC trial of treatment of hypertension in older adults: principal results. $B M$ 1992;304:405-12. (15 February.)

2 Kendall MJ. Treatment of hypertension in older adults. $B M J$ 1992; 304:639. (7 March.)

3 Yusuf S, Peto R, Lewis J, Collins R, Sleight P. Beta blockade during and after myocardial infarction: an overview of the randomised trials. Progress in Cardiovascular Diseases 1985;27:335-71.

4 ISIS-1 Collaborative Group. Randomised trial of intravenous atenolol among 16027 cases of suspected acute myocardial infarction: ISIS-1. Lancet 1986; ii: 57-66.

5 Boissel J-P, Leizorovicz A, Picolet H, Peyrieux J-C. Secondary prevention after high-risk acute myocardial infarction with
low-dose acebutolol. Am $f$ Cardiol 1990;66:251-60.

6 Cruickshank JM, Prichard BNC. Beta-blockers in clinical practice. Edinburgh: Churchill Livingstone, 1987:177.

7 Bax NDS, Lennard MS, Al-Asady S, Deacon CS, Tucker GT Woods HF. Inhibition of drug metabolism by $\beta$-adrenocepto antagonists. Drugs 1983;25(suppl 2):121-6.

8 Peto $R$. Why do we need systematic overviews of randomise trials? Statistics in Medicine 1987;6:233-40.

\section{Storing vaccines at the correct temperature}

SIR,-Yogini Thakker and Sheila Woods found that vaccines stored in community clinics and in general practice were exposed to temperatures that might reduce their potency. ${ }^{1}$ They concluded that adequate equipment and training for staff in maintaining the cold chain were essential for the success of an immunisation programme.

In Harrow I received a telephone call from a health visitor who was worried about the temperature of a particular general practitioner's refrigerator. Discussion with staff working in both general practice and community clinics showed that this was a fairly widespread problem.

I tackled the issue by producing a set of guidelines combined with a temperature char to record daily maximum and minimum temperatures. The chart was designed to be kept on or near each refrigerator in which vaccines were stored. Each clinic or surgery would designate a member of staff to be responsible for the

Hydrophilicity of $\beta$ blockers and its effect on long term mortality benefits after myocardial infarction

\begin{tabular}{|c|c|c|c|c|}
\hline $\begin{array}{l}\text { Distribution coefficient }\left(\mathrm{K}_{\mathrm{p}}\right) \text { in } o c t a n o l / \text { water } \\
\text { at } \mathrm{pH} 7 \cdot 4 \text { (range) }\end{array}$ & $\beta$ blockers & No of patients & Odds ratio & ( $95 \%$ confidence interval) \\
\hline $10 \cdot 0-100 \cdot 0$ & $\begin{array}{l}\text { Propranolol } \\
\text { Alprenolol }\end{array}$ & 6458 & 0.74 & $(0.63$ to 0.88$)$ \\
\hline $1 \cdot 0-10.0$ & $\begin{array}{l}\text { Timolol } \\
\text { Oxprenolol }\end{array}$ & 6314 & 0.77 & $(0.64$ to 0.92$)$ \\
\hline $0 \cdot 1-1 \cdot 0$ & $\begin{array}{l}\text { Pindolol } \\
\text { Acebutolol } \\
\text { Metoprolol }\end{array}$ & 6646 & 0.76 & $(0.63$ to 0.91$)$ \\
\hline $0 \cdot 01-0 \cdot 1$ & $\begin{array}{l}\text { Practolol } \\
\text { Atenolol } \\
\text { Sotalol }\end{array}$ & 5137 & $0 \cdot 82$ & $(0.68$ to 1.00$)$ \\
\hline
\end{tabular}

refrigerator and for record keeping. The guidelines on the chart give clear advice on how to care for the vaccines and refrigerator and what to do if something goes wrong or if advice is needed.

I approached Brent and Harrow Family Health Services Authority through its drug and therapeutics committee, and the idea was received enthusiastically. The chart has now been produced as an A3 size plastic laminated poster that can be wiped clean. It has been distributed, with a special pen, to all general practice surgeries and clinics in the area covered by Brent and Harrow Family Health Services Authority. It has been well received and has given rise to several inquiries about storing vaccines. I hope that it will make community staff more aware of the need to store vaccines correctly and will help to ensure that all vaccines retain their full potency until they are used.

I thank the members of the drug and therapeutics committee of Brent and Harrow Family Health Services Authority for their help and enthusiasm in funding the production of, and distributing, this chart.

Northwick Park Hospital,

PHILIPPA LEWIS

Harrow,

Middlesex HA1 3UJ

1 Thakker Y, Woods S. Storage of vaccines in the community; weak link in the cold chain? BMF 1992;304:756-8. (21 March.)

\section{Myeloma and benign intracranial hypertension}

SIR,-The report of $\mathbf{H}$ Wasan and colleagues on myeloma and benign intracranial hypertension provides insufficient data to justify their conclusions.' On the basis of the clinical history supplied, the diagnosis of benign intracranial hypertension in at least two of their cases is doubtful; few neurologists would accept dysphagia, dysarthria, psychomotor retardation, nystagmus, and unsteady gait as features compatible with this disease. No details of cerebrospinal fluid analysis are given, and there are no comments on computed tomographic appearances.

The authors have neglected to exclude the important possibility of dural sinus thrombosis, to which patients with myeloproliferative disorders are known to be susceptible. No mention is made in the report of investigations to elucidate such a diagnosis (contrast enhanced computed tomography, magnetic resonance imaging, or arteriography).

Finally, the authors' conclusion that all patients presenting with benign intracranial hypertension should be subjected to a myeloma screen, including bone marrow aspiration and trephine, is surprising. Most patients with benign intracranial hypertension are female; male patients with apparent benign intracranial hypertension should always be suspected of harbouring alternative pathology, particularly sinus thrombosis or diffuse meningeal tumour. Benign intracranial hypertension should therefore be a diagnosis of exclusion, especially in men, and bone marrow aspiration in typical female patients is not justified.

RICHARD J DAVENPORT ROGER E CULL

Neurology Clinic,

Royal Infirmary of Edinburgh,

Edinburgh EH3 9YW

Wasan H, Mansi JL, Benjamin S, Powles R, Cunningham D Myeloma and benign intracranial hypertension. BMF 1992 304:685. (14 March.)

AUTHOR'S REPLY, - We agree that dysphagia, dysarthria, and psychomotor retardation are atypical symptoms of benign intracranial hypertension. We do not attempt to attribute all symptoms to benign intracranial hypertension but have factually stated 